\title{
EDITORIAL
}

\section{Mind the gap}

\author{
The success of initiatives recently launched to help create more new treatments hinges on
} bridging the sociological divides that persist in drug discovery and development.

Reaching a half-century milestone is often a time for reflection, and so it was earlier this year when the $50^{\text {th }}$ issue of Nature Reviews Drug Discovery rolled off the presses. One thought in particular stood out: whether the original editorial mission of the journal is as relevant today as it was with the first issue. For any reader unfamiliar with this mission, the journal was launched to a large degree on the premise that R\&D productivity was being stifled by the lack of communication between the different disciplines involved in drug discovery and development. Providing a forum for the very best content spanning all areas of the drug discovery and development spectrum would, it was hoped, give readers a chance to bump into pieces of information that could change the way they think about a problem.

On reflection, it seems clear that the need to break down 'compartmentalization' is still as important, if not more so. Fifty issues on, the industry is under unprecedented pressure that shows no immediate signs of easing. The annual number of approved new molecular entities is still wallowing at all-time low levels, and added to this pharmaceutical companies now face weakened earnings and a worsening public image.

These are certainly extraordinary times for the pharmaceutical industry, and extraordinary times call for extraordinary measures. Companies are devoting more resources than ever towards R\&D - around US $\$ 51$ billion in 2005 according to a recent Burrill \& Company report - and are trying several ways of boosting R\&D productivity, such as the burst of merger and acquisition activity occurring in the birthplace of the industry, Germany, and the growing outsourcing of chemistry in Asia and Eastern Europe that are described in the news stories on pages $361-363$ in this issue. But such strategies are in danger of just patching up a broken system: throwing more resources and scientists at a problem will not necessarily guarantee success if existing methodologies and technologies are not up to scratch.

Reducing any technological gaps requires even more barriers to be eroded, as it needs greater cooperation not just between disciplines, but between competitors. This will require a momentous change in the sociology of drug discovery and development, but there are encouraging signs that companies are willing to break down barriers for the common good. For example, as part of the FDA's Critical Path Initiative (as reported in page 271 of the last issue), eight major pharmaceutical companies have joined the Predictive Safety Testing Consortium, under the auspices of the Critical Path Institute, based in Tucson, Arizona, to share internally developed laboratory methods that can predict the safety of new treatments before they are tested in humans. Another initiative with similar goals - the Center for Biomedical Innovation (CBI), a network of several faculties within the Massachusetts Institute of Technology - is discussed on page 368 in this issue. The CBI aims to provide a safe harbour for major players from business, government and academia to discuss and address key problems affecting the industry, such as monitoring drug safety before and after approval, and re-evaluating $\mathrm{R} \& \mathrm{D}$ models.

To reach their full potential, though, these initiatives will require true commitment across a number of sectors, which means addressing perhaps the biggest sociological divide in pharmaceutical sciences - the gap between academic and industry scientists. Put bluntly, the sooner academic and industry scientists destroy the stereotypes they hold of each other, the more likely that drug discovery and development will truly evolve to succeed in the $21^{\text {st }}$ century. Industry needs to break down its natural defensiveness and be more willing to accept that creativity in drug discovery and development is increasingly likely to come from external sources. Similarly, academic scientists need to appreciate industry timelines, and accept that the journey from a Nature, Science or Cell paper describing a potential therapeutic target to an approved drug is long, expensive and much more likely to fail than succeed.

Engendering this sociological change won't be straightforward. Bridging technological gaps to address the current pipeline malaise will be most likely if researchers can unite around scientific philosophies, rather than acting as 'tribes' with similar interests that often turn out to be disparate. The more academia and industry persist in being like - to paraphrase Winston Churchill - two scientific nations divided by a common language, the more likely the next 50 issues of this journal will continue to see the business of creating new and better drugs being all the more poorer for it. 